\title{
Comparison of Hearing Outcomes of Systemic Steroid Monotherapy and Intratympanic Steroid Combined Treatment in Idiopathic Sudden Sensorineural Hearing Loss
}

\author{
Kyungil Jang, So Yun Lim, Eun-Ju Jeon, and Hyun Jin Lee \\ Department of Otorhinolaryngology-Head and Neck Surgery, College of Medicine, The Catholic University of Korea, Seoul, Korea
}

돌발성 난청 환자에서 전신 스테로이드 단독요법과 고실 내 스테로이드 병용요법의 치료 효과 비교

장경일 · 임소연 · 전은주 · 이현진

가톨릭대학교 의과대학 이비인후과학교실

Received June 22, 2020

Revised July 26, 2020

Accepted November 3, 2020

Address for correspondence

Hyun Jin Lee, MD

Department of Otorhinolaryngology-

Head and Neck Surgery,

Incheon St. Mary's Hospital,

College of Medicine,

The Catholic University of Korea,

56 Dongsu-ro, Bupyung-gu,

Incheon 21431, Korea

Tel $+82-32-280-5151$

Fax $+82-32-280-5821$

E-mail idgenesis@naver.com
Background and Objectives Steroid treatment is used as a main treatment modality for sudden sensorineural hearing loss (SSNHL). Intratympanic injection of steroid (ITS) has been used and its therapeutic efficacy reported as being comparable to the systemic steroid administration (SS). This study compares the hearing outcomes of using ITS and SS simultaneously and SS alone.

Subjects and Method Retrospective chart review was performed for 146 patients with SSNHL. The patients were divided into 2 groups according to the method of treatment (SS and ITS simultaneously vs. SS alone). The inclusion criteria were starting treatment within 7 days after onset, and follow up pure tone audiometry at least 4 weeks after treatment. Hearing gain for pure tone threshold of each frequency and average of 4 frequencies $(500 \mathrm{~Hz}, 1000 \mathrm{~Hz}$, $2000 \mathrm{~Hz}$, and $4000 \mathrm{~Hz}$ ) were compared between both groups.

Results The improvement in PTA at 1-month follow-up was $27.3 \pm 20.0 \mathrm{~dB}$ HL in the simultaneous group and $19.1 \pm 19.5 \mathrm{~dB}$ HL in the SS alone group; this was not statistically significant Complete or partial recovery at 1-month follow-up was observed in $65.3 \%$ of the simultaneous group and $69.6 \%$ of the SS alone group; this was also not significant.

Conclusion There was no significant difference in hearing outcomes between the simultaneous and SS alone group. The simultaneous therapy does not appear to be superior to the SS alone therapy. Further studies using more population and longer follow-up periods are necessary.

Korean J Otorhinolaryngol-Head Neck Surg 2021;64(3):155-60

Key Words Hearing loss · Inner ear · Steroid · Hearing loss, sudden.

\section{서 론}

돌발성 난청은 갑작스러운 청력 저하가 발생하는 질환으로, 72시간 내에 3개 이상의 연속된 주파수에서 $30 \mathrm{~dB}$ 이상의

This is an Open Access article distributed under the terms of the Creative Commons Attribution Non-Commercial License (https://creativecommons.org/licenses/by-nc/4.0) which permits unrestricted non-commercial use, distribution, and reproduction in any medium, provided the original work is properly cited.
감각신경성 청력 저하가 나타나는 것으로 정의한다. ${ }^{1}$ 치료 시 기가 늦어질 경우 청력 예후가 불량할 수 있으며, 환자의 삶 의 질이 저하될 수 있기 때문에 즉각적인 진단과 치료가 필요 하다. ${ }^{23)}$ 돌발성 감각신경성 난청의 일차 치료법으로 전신적 스테로이드 치료와 고실 내 스테로이드 주입술이 사용되고 있으며, 두 가지 치료 모두 효과가 비슷한 것으로 알려져 있 다.-8) 전신적 스테로이드 치료와 고실 내 스테로이드 주입술 
을 동시에 시행하는 것과 전신적 스테로이드 치료 단독요법을 비교했을 때, 병합요법이 더 좋은 청력 회복을 보인다는 결과 가 다수 보고되었다. ${ }^{9-13)}$ 하지만 고실 내 스테로이드 주입을 동시에 시행했을 때 추가적인 이득이 없다는 연구 결과도 있 다. ${ }^{14-16)}$ 따라서 본 연구는 전신적 스테로이드 단독 치료와 고 실 내 스테로이드를 병행하였을 때의 청력 회복 정도를 비교 해 보고자 한다.

\section{대상 및 방법}

2015년 1월 2017년 12월까지 본원 이비인후과에서 돌발성 난청 진단하에 치료를 받은 환자를 대상으로 후향적 의무기 록 분석을 하였다. 대상 환자의 선정 기준은 뚜렷한 원인 없 이 3일 이내에 순음청력검사상 3개의 연속되는 주파수에서 $30 \mathrm{~dB}$ 이상의 감각신경성 난청 소견을 보이는 환자 중 발병 후 1 주 이내에 치료를 시작한 환자로 하였다. 이 중 $10 \mathrm{~dB}$ 이 상의 전음성 난청이 있는 환자, 뇌 병변 혹은 외상에 의한 난 청 환자, 메니에르병 및 중이염의 과거력이 있는 환자는 분석 대상에서 제외하였다. 총 146 명이 위 조건에 부합하였으며, 이 중 경구 스테로이드제와 고실 내 스테로이드 주입술을 병 행하여 시행한 군을 $\mathrm{A}$ 군, 경구 스테로이드제만 투약한 군을 $\mathrm{B}$ 군으로 나누었다.

두 군 모두 prednisolone(Solondo ${ }^{\circledR}$, Yuhan Corp., Seoul, Korea)을 제1일에서 제5일까지 환자 개별 몸무게에 따라 하루 $1 \mathrm{~kg}$ 당 $1 \mathrm{~mL}$ 의 용량으로 오전, 오후 총 2회로 경구 분복 투 여하였고, 최대 하루 $80 \mathrm{mg}$ 을 초과하지 않도록 하였다. 제6, 7 일에 용량을 절반으로 줄여서 투약하였고, 제 8,9 일에 오전 $10 \mathrm{mg}$, 오후 $10 \mathrm{mg}$ 으로 총 $20 \mathrm{mg}$ 를 분복 투여하였고, 제 10 일에 하루 총 $10 \mathrm{mg}$ 투여하여, 총 10 일간 투여하였다. 고실 내 스테로이드 주입술은 dexamethasone(Dexamethasone phosphate disodium $^{\circledR}, 5 \mathrm{mg} / \mathrm{mL}$, Huons Medical, Seoul, Korea)을 사용하였고, 2일 간격으로 최소 3회 이상 시행하였 으며, $1 \mathrm{~mL}$ 투베르쿨린 시린지에 25 게이지 바늘을 부착하여 고막 전하방부에 주입하였고, 1 회 주입량은 약 $0.5 \mathrm{~mL}$ 였다. 약물 주입 후 앙와위에서 주입한 반대 측으로 고개를 돌린 채 30 분 정도 유지시켰다.

청력 평가는 순음청력검사를 치료 시작 전 1 회, 치료 시작 후 2주일째 1 회, 치료 시작 후 1 개월째 1회 시행하였으며, 각 각의 청력역치 호전도에 따라 치료 효과를 판정하였다. 청력 역치의 평균값은 $0.5,1,2$ 및 $4 \mathrm{kHz}$ 의 6분법으로 계산하였 으며, 2012 AAO-HNSF Clinical Practice Guideline: Sudden Hearing Loss에 따라 치료 호전 여부를 판정하였다. ${ }^{17)}$ 치료 후 청력역치가 정상 측 순음청력역치의 $10 \mathrm{~dB}$ 이내로 회
복된 경우를 완전회복군(complete recovery), 치료 전 순음청 력역치의 $50 \%$ 이내로 회복되거나, 청력역치 호전도가 $10 \mathrm{~dB}$ 이상인 경우를 부분회복군(partial recovery)으로 분류하였다. 부분회복군 중 청력이 $50 \mathrm{~dB}$ 이하로 회복되는 경우 의미 있 는 청력 회복으로 판정하였다. 또한, 청력역치 호전도가 $10 \mathrm{~dB}$ 미만인 경우를 미회복군(no improvement)으로 분류하였다. 완전회복군 및 부분회복군을 모두 포함하여 청력 회복으로 간주하였을 때, 두 군 간 회복률의 차이가 나타나는지 비교 하였다. 또한 A군 내에서 고실 내 스테로이드 주입술을 4회 이하로 시행한 군과 5회 이상 시행한 군을 별도로 구분하여 회복률 및 주파수별 호전 정도의 차이가 나타나는지 분석하 였다.

통계적 분석은 SPSS 24.0(IBM Corp., Armonk, NY, USA) 을 통해 $\mathrm{t}$-검정 혹은 Mann-Whitney U test, 카이 제곱 분석 및 Fisher's exact test를 시행하여 두 군을 비교하였다. $p$ 값 이 0.05 이하인 경우에 유의한 차이가 있는 것으로 판정하였 다. 각 자료의 평균은 중앙값과 표준편차로 표기하였다.

\section{결 과}

$\mathrm{A}$ 군은 총 55 명으로 평균 나이 $53.8 \pm 14.5$ 세, 남녀 성비는 $26: 29$, 병변 방향은 우측과 좌측 비 $27: 28$ 이었다. 발병 후 초 기 치료까지의 기간은 평균 $3.1 \pm 2.1$ 일이었으며, 어지럼이 있 는 경우는 11 명(20\%), 이명이 있는 경우는 26명(47.2\%)이었다. 6 분법상 초기 순음청력역치의 평균은 $68.2 \pm 23.5 \mathrm{~dB}$, 순음청 력검사 패턴에 따라 상승형 7명(12.7\%), 편평형 25명(45.4\%), 하강형 23명(48.2\%)이었다. 당뇨가 있는 환자는 6명(10.9\%), 고혈압이 있는 환자는 14 명(25.4\%)이었고, 고실 내 스테로이 드 주입술 평균 시행 횟수는 $5.5 \pm 2.2$ 회였다. B군은 총 91 명 으로 평균 나이 $51.5 \pm 14.8$ 세, 남녀 성비는 $54: 47$, 병변 방향 은 우측과 좌측 비 45:46이었다. 발병 후 초기 치료까지의 기 간은 평균 $2.9 \pm 2.2$ 일이었으며, 어지럼이 있는 경우는 24 명 (26.3\%), 이명이 있는 경우는 62명(68.1\%), 6분법상 초기 순 음청력역치의 평균은 $55.9 \pm 25.5 \mathrm{~dB}$, 순음청력검사 패턴에 따라 상승형 29명(31.8\%), 편평형 21명(23.0\%), 하강형 41명 (45.0\%)이었다. 당뇨가 있는 환자는 10 명(10.9\%), 고혈압이 있 는 환자는 23명(25.2\%)이었다. 양 군 사이의 연령, 성별, 병변 방향, 발병 후 초기치료까지의 기간, 초기 순음청력역치, 초기 어지럼 또는 이명 동반 유무, 당뇨 또는 고혈압 동반 유무에 대해 카이 제곱 검정 및 $\mathrm{t}$-검정을 시행하였다. $\mathrm{A}$ 군의 치료 전 순음청력역치가 $\mathrm{B}$ 군에 비해 유의하게 높았으며 $(p<0.05)$, 이 외의 다른 요인들은 유의한 통계학적 차이는 없었다(Table 1). 


\section{2주 치료 후 청력 호전 비교}

청력역치 호전도는 $\mathrm{A}$ 군은 $22.6 \pm 23.4 \mathrm{~dB}, \mathrm{~B}$ 군은 $17.2 \pm 19.6$ $\mathrm{dB}$ 로 양 군 간의 유의미한 통계학적 차이는 없었다 $(p>0.05)$ (Fig. 1A). 각 주파수별 청력역치 호전도를 양 군간 비교하였

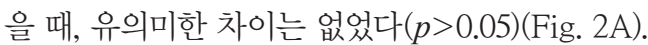

치료 2주 후 회복 정도를 2012 AAO-HNSF Clinical Practice Guideline에 따라 비교했을 때, A군에서 완전회복을 보 인 경우는 20 명(36.3\%), 유의미한 부분회복을 보인 경우는 10명(18.1\%), 무의미한 부분회복을 보인 경우는 6명(10.9\%)이 었고, 회복이 없는 경우는 19명(34.5\%)이었다. B군에서 완전 회복을 보인 경우는 48명(52.7\%), 유의미한 부분회복을 보인 경우는 6명(6.6\%), 무의미한 부분회복을 보인 경우는 4명 (4.4\%)이었고, 회복이 없는 경우는 33명(36.2\%)이었다. 완전회 복군과 부분회복군을 청력 회복으로 간주하여 양 군 간의 회 복률의 차이를 카이 제곱 검정하였을 때, A군은 36명(65.3\%),

Table 1. Subject demographic data

\begin{tabular}{lccc}
\hline \multicolumn{1}{c}{ Characteristics } & $\begin{array}{c}\text { Group A (\%) } \\
(\mathrm{n}=55)\end{array}$ & $\begin{array}{c}\text { Group B (\%) } \\
(\mathrm{n}=91)\end{array}$ & p-value \\
\hline Age (y) & $58.3 \pm 14.5$ & $51.5 \pm 14.8$ & 0.37 \\
Sex (M:F) & $26: 29$ & $54: 47$ & 0.15 \\
Right:left & $27: 28$ & $45: 46$ & 0.86 \\
Duration from onset (day) & $3.1 \pm 2.1$ & $2.9 \pm 2.2$ & 0.69 \\
Vertigo & $11(20.0)$ & $24(26.3)$ & 0.38 \\
Tinnitus & $26(47.2)$ & $62(68.1)$ & 0.74 \\
Diabetes & $6(10.9)$ & $10(10.9)$ & 0.98 \\
Hypertension & $14(25.4)$ & $23(25.2)$ & 0.98 \\
Initial hearing level (dB HL) & $68.2 \pm 23.5$ & $55.9 \pm 25.5$ & 0.01 \\
Pattern of audiogram & & & 0.71 \\
$\quad$ Ascending & $7(12.7)$ & $29(31.8)$ & \\
$\quad$ Flat & $25(45.4)$ & $21(23.0)$ & \\
$\quad$ Descending & $23(48.2)$ & $41(45.0)$ & \\
Number of ITS & $5.5 \pm 2.2$ & & \\
\hline
\end{tabular}

M: male, F: female, ITS: intratympanic injection of steroid

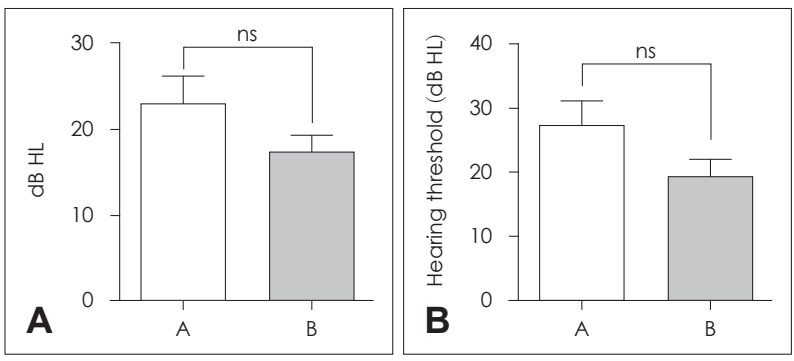

Fig. 1. Comparison of hearing gain between simultaneous SS with ITS and SS alone. There was no significant difference in hearing gain between the two groups after 2 weeks $(p>0.05)(A)$. There was no significant difference in hearing gain between the two groups after 1 month of treatment $(p>0.05)(B)$. ns: not significant, SS: systemic steroid administration, ITS: intratympanic injection of steroid.
$\mathrm{B}$ 군은 58명(63.7\%)으로 유의미한 통계학적 차이는 없었다 $(p>0.05)$ (Table 2).

\section{1개월 치료 후 청력 호전 비교}

청력역치 호전도는 $\mathrm{A}$ 군은 $27.3 \pm 20.0 \mathrm{~dB}, \mathrm{~B}$ 군은 $19.1 \pm 19.5$ $\mathrm{dB}$ 로 양 군 간의 유의미한 통계학적 차이는 없었다 $(p>0.05)$ (Fig. 1B). 각 주파수별 청력역치 호전도를 양 군간 비교하였 을 때, 유의미한 통계학적 차이는 없었다( $p>0.05)$ (Fig. 2B). 치료 1개월 후 청력 회복 정도를 2012 AAO-HNSF Clinical Practice Guideline에 따라 비교하였을 때, $\mathrm{A}$ 군에서 완전회 복을 보인 경우는 13 명(38.2\%), 부분회복을 보인 경우는 7명 (20.5\%)로 모두 유의미한 부분회복을 보였고, 회복이 없는 경 우는 14 명 $41.1 \%)$ 이었다. B군은 총 44 명 중 완전회복을 보인 경우는 6명(13.6\%), 유의미한 부분회복을 보인 경우는 18명 (40.9\%), 무의미한 부분회복을 보인 경우는 5명(11.3\%)이었고, 회복이 없는 경우는 15 명(36.2\%)이었다. 완전회복군과 부분 회복군을 청력 회복으로 간주하여 양 군 간의 회복률의 차 이를 카이 제곱 검정하였을 때, 유의미한 통계학적 차이는 없 었다 $(p>0.05)$ (Table 3).

\section{ITS 시행 횟수에 따른 청력 호전 비교}

$\mathrm{A}$ 군에서 총 고실 내 스테로이드 주입술을 받은 횟수에 따 라 4 회 이하 시행한 군과 5 회 이상 시행한 군으로 분류하였다. 양 군의 청력 회복 정도를 2012 AAO-HNSF Clinical Practice Guidelines에 따라 분류하면, 4 회 이상 시행한 군은 총 24 명 중 완전회복을 보인 경우는 12 명(50.0\%), 유의미한 부 분회복을 보인 경우는 1명(4.1\%), 무의미한 부분회복을 보인 경우는 2명(8.3\%)이었고, 회복이 없는 경우는 9명(37.5\%)이었 다. 5 회 이상 시행한 군은 총 21 명 중 완전회복을 보인 경우는 9명(29.0\%), 유의미한 부분회복을 보인 경우는 7명(22.5\%), 무의미한 부분회복을 보인 경우는 6명(19.3\%)이었고, 회복이 없는 경우는 9명(29.0\%)이었다. 완전회복군과 부분회복군을 청력 회복으로 간주하여 양 군 간의 회복률의 차이를 카이 제곱 검정하였을 때, 유의미한 통계학적 차이는 없었다 $(p>$ 0.05)(Table 4).

고실 내 스테로이드 주입술 시행 횟수에 따른 각각의 청력 호전도를 선형회귀분석을 통해 비교하였을 때, 치료 2주 후 $(p=0.93)$ 와 치료 1 개월 후 $(p=0.38)$ 모두에서 고실 내 스테로 이드 주입술 시행 횟수에 따른 청력 호전도의 유의미한 상관 관계는 없었다(Fig. 3). 

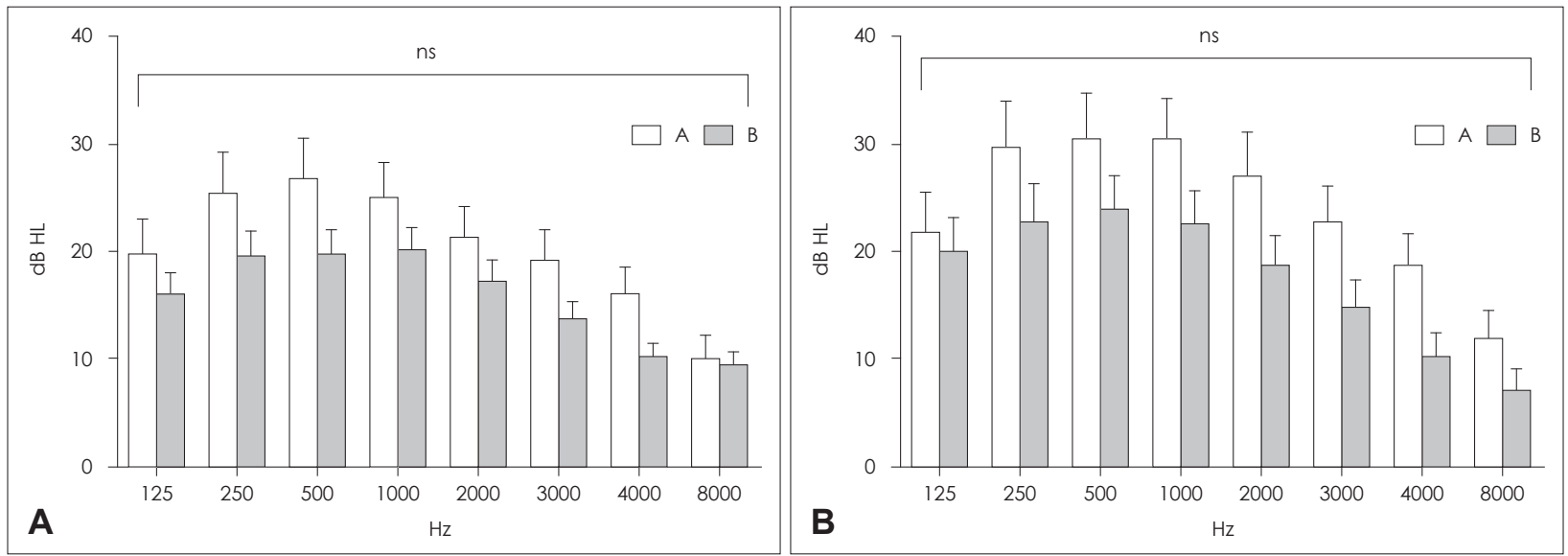

Fig. 2. Hearing gain for each frequency at post-treatment 2 weeks and 1 month. There was no significant difference in hearing gain for each frequency between the two groups after 2 weeks $(p>0.05)(A)$. There was no significant difference in hearing gain for each frequency between the two groups after 1 month of treatment $(p>0.05)(B)$. ns: not significant.

Table 2. Hearing recovery after 2 weeks

\begin{tabular}{lcc}
\hline \multicolumn{1}{c}{ Outcome } & Group A $(\mathrm{n}=55)(\%)$ & Group B $(\mathrm{n}=91)(\%)$ \\
\hline Complete recovery & $20(36.3)$ & $48(52.7)$ \\
Partial recovery & & \\
Meaningful & $10(18.1)$ & $6(6.6)$ \\
Non-meaningful & $6(10.9)$ & $4(4.4)$ \\
No recovery & $19(34.5)$ & $33(36.2)$ \\
\hline
\end{tabular}

Comparison of recovery rates between the outpatient and inpatient groups according to the AAO-HNSF Clinical Practice Guidelines

Table 3. Hearing recovery after 1 month

\begin{tabular}{lcc}
\hline \multicolumn{1}{c}{ Outcome } & Group A $(\mathrm{n}=55)(\%)$ & Group B $(\mathrm{n}=91)(\%)$ \\
\hline Complete recovery & $26(47.2)$ & $39(42.8)$ \\
Partial recovery & & \\
Meaningful & $7(12.7)$ & $19(20.8)$ \\
Non-meaningful & $3(5.4)$ & $6(6.5)$ \\
No recovery & $19(34.5)$ & $27(29.6)$
\end{tabular}

Comparison of recovery rates between the outpatient and inpatient groups according to the AAO-HNSF Clinical Practice Guidelines

\section{고 찰}

본 연구는 경구 스테로이드와 고실 내 스테로이드 주입술 을 동시에 병행한 군(A군)과 경구 스테로이드만 복용한 군(B 군)의 청력 회복 정도를 $2012 \mathrm{AAO}-\mathrm{HNSF}$ Clinical Practice Guideline에 따라 각각 치료 후 2주, 1개월 뒤 비교하였다. 치 료 2주 후와 치료 1개월 후에서 $\mathrm{A}$ 군과 $\mathrm{B}$ 군 간에 청력역치 호 전도는 유의미한 통계학적 차이는 없었다 $(p>0.05)$. 완전회복 군과 부분회복군을 청력 회복으로 간주하여 두 군 간의 회 복률의 차이를 비교하였을 때, 유의미한 통계학적 차이는 없 었다 $(p>0.05)$.
Table 4. Hearing recovery after 2 weeks (according to the number of intratympanic injection of steroid)

\begin{tabular}{lcc}
\hline \multicolumn{1}{c}{ Outcome } & $\begin{array}{c}\text { Less than } 4 \text { times } \\
(\mathrm{n}=24)(\%)\end{array}$ & $\begin{array}{c}\text { More than 5 times } \\
(\mathrm{n}=21)(\%)\end{array}$ \\
\hline Complete recovery & $12(50.0)$ & $9(29.0)$ \\
Partial recovery & & \\
Meaningful & $1(4.1)$ & $7(22.5)$ \\
Non-meaningful & $2(8.3)$ & $6(19.3)$ \\
No recovery & $9(37.5)$ & $9(29.0)$ \\
\hline
\end{tabular}

Comparison of recovery rates between the outpatient and inpatient groups according to the AAO-HNSF Clinical Practice Guidelines

전신 스테로이드 투약 및 고실 내 스테로이드 주입술을 병 행한 치료 결과에 대해서 다양한 결과들이 보고되었다. Battalglia 등 ${ }^{9}$ 은 경구 스테로이드 단독 투약한 군, 고실 내 스테 로이드 주입술 단독 시행한 군, 두가지를 병행한 군의 치료 4 주 후 청력 회복을 비교하였고, 병행치료한 군에서 나머지 두 군보다 회복률이 유의하게 높았다고 보고하였다. Jung 등미 은 후향적 증례 대조군 연구로 전신 스테로이드만 투약한 군 과 고실 내 스테로이드 주입술을 병행한 군을 비교하였다. 치 료 후 10 일 째에는 양 군 간에 유의한 차이는 없었으나, 90 일 이후에는 병행치료 군에서 전 주파수에 걸쳐 더 높은 회복 률을 보였다고 보고하였다. Gundogan 등 ${ }^{13)}$ 은 전향적 무작위 비교 연구로 경구 스테로이드 단독 투약한 군과 고실 내 스테 로이드 주입술을 병행한 군을 비교하였다. 치료 시작 후 2주, 4주 째에 각각 청력 호전도를 Siegel's criteria에 따라 비교하 였고, 병행치료 군에서 전 주파수에 걸쳐 더 높은 회복률을 보였다고 보고하였다.

Ahn 등 ${ }^{14}$ 은 전향적 연구로 경구 스테로이드 단독 투약한 군 과 고실 내 스테로이드 주입술을 병행한 군을 비교하였다. 치 료 시작 후 3개월째에 청력역치 호전도를 Siegel's criteria에 

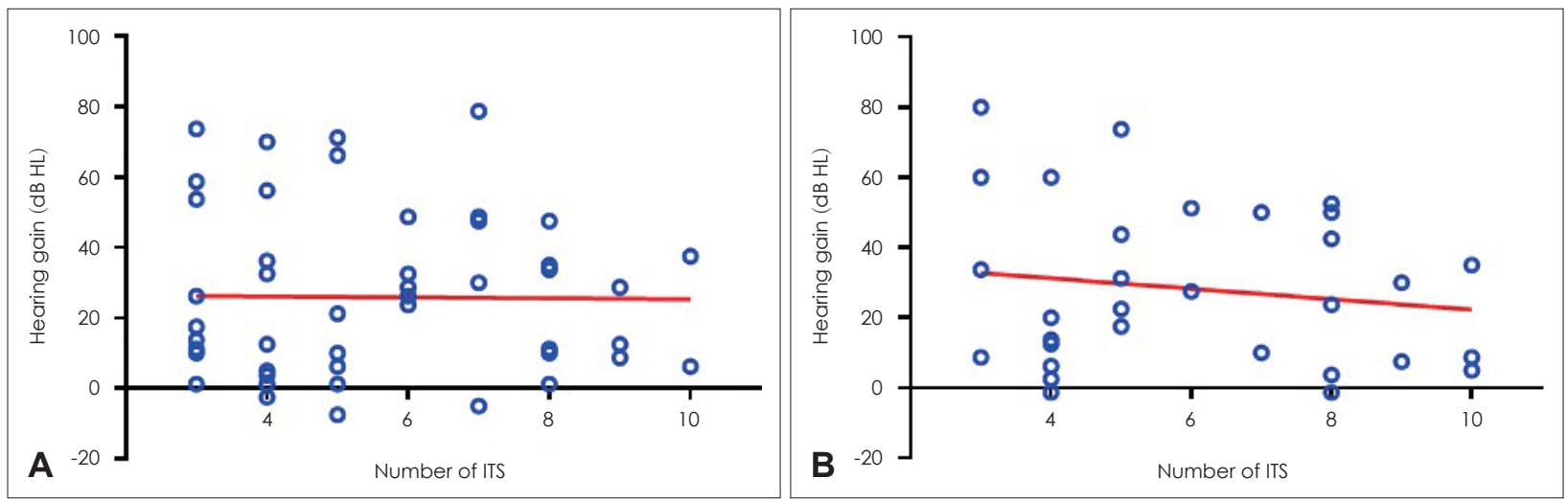

Fig. 3. Hearing gain according to the number of ITS in the simultaneous SS with ITS group. There was no significant difference in hearing gain after 2 weeks $(p>0.05)(A)$. There was no significant difference in hearing gain after 1 month of treatment $(p>0.05)(B)$. SS: systemic steroid administration, ITS: intratympanic injection of steroid.

따라 비교하였고, 두 군 간에 유의한 차이는 없었다. Ashtiani 등 ${ }^{15)}$ 은 경구 스테로이드 단독 투약한 군, 고실 내 스테로이드 주입술 단독 시행한 군, 그리고 두 가지를 같이 병행한 군으 로 나누었고, 치료 시작 4주 후에 청력 회복률은 세 군 간에 유의미한 차이가 없었다고 보고하였다. Baysal 등히은 경구 스테로이드 단독 투약한 군과 고실 내 스테로이드 주입술을 병행한 군을 비교하였다. 치료 시작 후 1 개월째에 청력역치 호전도는 두 군 간에 유의미한 차이가 없었다고 보고하였다.

이와 같이 전신 스테로이드와 고실 내 스테로이드 주입술 병행 치료 결과는 선행 연구에서 다양하게 보고되었다. 하지 만 과거 연구들은 청력 호전도 비교 기준 또한 다양하였다. 반대 측 청력의 $5 \mathrm{~dB}$ 이내, 병변 측 청력의 $10 \mathrm{~dB}$ 이상 호전, Siegel's criteria ${ }^{18)}$ 또는 연구자가 설정한 자체적인 기준을 적 용하기도 하였다. 하지만 본 연구는 청력 회복 정도를 2012 AAO-HNSF Clinical Practice Guideline ${ }^{17)}$ 따라 분석하였고, 병행 치료와 단독 치료 사이에 청력 호전에는 유의한 차이가 없었음을 확인하였다.

$\mathrm{A}$ 군에서 고실 내 스테로이드 주입술을 4회 이하로 시행한 군과 5 회 이상 시행한 군을 비교하였을 때, 청력 회복의 유의 미한 통계학적 차이는 없었다 $(p>0.05)$. 또한 고실 내 스테로 이드 주입술 횟수에 따른 청력 회복에 유의한 차이는 없었 다. 2012 AAO-HNSF Clinical Practice Guideline ${ }^{17}$ 에 따르면 고실 내 스테로이드 주입술은 초 치료 실패 시 또는 치료 후 불완전한 회복 시 시행하라고 권고되어 있다. 주입술의 횟수 를 특별히 정의하지는 않았으며, 참고로 제시된 다양한 연구 에서는 3회 또는 4회 고실 내 스테로이드 주입술을 시행하였 다. 본 연구는 고실 내 스테로이드 주입술을 경구 스테로이드 와 동시에 초기 치료로 시행했을 때의 효과를 확인하고자 하 였으나 유의한 청력 호전 결과는 없었다. 따라서 고실 내 스 테로이드 주입술은 초기 병행치료보다는 구제 치료로 시행되
어야 하겠다.

본 연구는 후향적 의무기록 분석이기 때문에 두 군이 무작 위 배정되지 않았다는 한계점이 있다. $\mathrm{A}$ 군의 치료 전 초기 순 음청력역치가 $\mathrm{B}$ 군에 비해 유의하게 높았으며, 이는 치료 전 초기 청력 저하가 심했을 경우 고실 내 스테로이드 주입술 병 행이 더 많았음을 시사한다. 이러한 한계점을 보완하고자 청 력 저하 정도에 따라 2012 AAO-HNSF Clinical Practice Guideline(class A, PTA $<30 \mathrm{~dB}$ and SDS $>70 \%$; class B, PTA $>30 \mathrm{~dB}$ and $<50 \mathrm{~dB}$ and SDS $>50 \%$; class $\mathrm{C}$, PTA $>50 \mathrm{~dB}$ and SDS $>50 \%$; Class D PTA any level and SDS $<50 \%$ )와 같이 청력 저하 정도를 분류하여 추가 분석을 시행 했다. ${ }^{19)}$ 각 군의 class별로 치료 한 달 후의 청력 회복 정도를 카이 제곱 분석했을 때, 모든 class에서 유의미한 차이는 나 타나지 않았다. 본 연구는 치료 시작 후 1 개월까지의 단기간 추적 관찰 결과만 비교하였으며, 치료 후 3 개월 이상까지의 장기적 결과는 비교하지 못했다. 본 연구에서는 구제치료의 효과까지 고려하지 않았기 때문에 추후 고실 내 주입술 동시 치료 또는 경구 스테로이드 단독 치료 후 회복이 되지 않은 환자들에게는 추가적인 고실 내 스테로이드 구제 치료가 필요 하겠다. 결론적으로 본 연구에서 경구 스테로이드제와 고실 내 스테로이드 주입술을 병행하여 시행한 군과 경구 스테로 이드제만 투약한 군 간에 청력 호전도에 유의미한 차이가 없 었으며, 더 많은 증례와 장기 추적 기간을 포함한 추가 연구 가 필요할 것으로 보인다.

\section{Acknowledgments}

This work was supported by a National Research Foundation (NRF) of Korea grant funded by the Korean government (MSIT) (2020R1C1C1005965).

\section{Author Contribution}

Conceptualization: Eun-Ju Jeon, Hyun Jin Lee. Data curation: 
Kyungil Jang, So Yun Lim, Hyun Jin Lee. Formal analysis: So Yun Lim, Eun-Ju Jeon, Hyun Jin Lee. Funding acquisition: Hyun Jin Lee. Investigation: Hyun Jin Lee. Methodology: Eun-Ju Jeon. Project administration: Hyun Jin Lee. Supervision: Eun-Ju Jeon. Validation: Hyun Jin Lee. Visualization: Hyun Jin Lee. Writing — original draft: Kyungil Jang, Hyun Jin Lee. Writing-review \& editing: Hyun Jin Lee.

\section{ORCID}

Hyun Jin Lee https://orcid.org/0000-0003-3826-8830

\section{REFERENCES}

1) Wilson WR, Byl FM, Laird N. The efficacy of steroids in the treatment of idiopathic sudden hearing loss. A double-blind clinical study. Arch Otolaryngol 1980;106(12):772-6.

2) Stew BT, Fishpool SJ, Williams H. Sudden sensorineural hearing loss. Br J Hosp Med (Lond) 2012;73(2):86-9.

3) Chau JK, Lin JR, Atashband S, Irvine RA, Westerberg BD. Systematic review of the evidence for the etiology of adult sudden sensorineural hearing loss. Laryngoscope 2010;120(5):1011-21.

4) Chandrasekhar SS, Tsai Do BS, Schwartz SR, Bontempo LJ, Faucett EA, Finestone SA, et al. Clinical practice guideline: Sudden hearing loss (update). Otolaryngol Head Neck Surg 2019; 161(1_suppl):S1-45.

5) Conlin AE, Parnes LS. Treatment of sudden sensorineural hearing loss: I. A systematic review. Arch Otolaryngol Head Neck Surg 2007;133(6):573-81.

6) Seggas I, Koltsidopoulos P, Bibas A, Tzonou A, Sismanis A. Intratympanic steroid therapy for sudden hearing loss: A review of the literature. Otol Neurotol 2011;32(1):29-35.

7) Han CS, Park JR, Boo SH, Jo JM, Park KW, Lee WY, et al. Clinical efficacy of initial intratympanic steroid treatment on sudden sensorineural hearing loss with diabetes. Otolaryngol Head Neck Surg 2009;141(5):572-8.

8) Hong SM, Park CH, Lee JH. Hearing outcomes of daily intratympanic dexamethasone alone as a primary treatment modality for ISSHL. Otolaryngol Head Neck Surg 2009;141(5):579-83.

9) Battaglia A, Burchette R, Cueva R. Combination therapy (intratympanic dexamethasone + high-dose prednisone taper) for the treatment of idiopathic sudden sensorineural hearing loss. Otol
Neurotol 2008;29(4):453-60.

10) Jung DJ, Park JH, Jang JH, Lee KY. The efficacy of combination therapy for idiopathic sudden sensorineural hearing loss. Laryngoscope 2016;126(8):1871-6.

11) Baek MK, Cho CH, Bang YJ, Oh NR, Baek MJ, Lee JH. Hearing outcomes and prognostic factors in idiopathic sudden sensorineural hearing loss patients with combined intratympanic and systemic steroid therapy. Korean J Otorhinolaryngol-Head Neck Surg 2018; 61(5):242-6.

12) Arastou S, Tajedini A, Borghei P. Combined intratympanic and systemic steroid therapy for poor-prognosis sudden sensorineural hearing loss. Iran J Otorhinolaryngol 2013;25(70):23-8.

13) Gundogan O, Pinar E, Imre A, Ozturkcan S, Cokmez O, Yigiter AC. Therapeutic efficacy of the combination of intratympanic methylprednisolone and oral steroid for idiopathic sudden deafness. Otolaryngol Head Neck Surg 2013;149(5):753-8.

14) Ahn JH, Yoo MH, Yoon TH, Chung JW. Can intratympanic dexamethasone added to systemic steroids improve hearing outcome in patients with sudden deafness? Laryngoscope 2008;118(2):279-82.

15) Ashtiani MK, Firouzi F, Bastaninejad S, Dabiri S, Nasirmohtaram S, Saeedi N, et al. Efficacy of systemic and intratympanic corticosteroid combination therapy versus intratympanic or systemic therapy in patients with idiopathic sudden sensorineural hearing loss: A randomized controlled trial. Eur Arch Otorhinolaryngol 2018; 275(1):89-97.

16) Baysal E, Tunç O, Baglam T, Durucu C, Oz A, Karatas ZA, et al. Systemic steroid versus combined systemic and intratympanic steroid treatment for sudden sensorineural hearing loss. J Craniofac Surg 2013;24(2):432-4.

17) Stachler RJ, Chandrasekhar SS, Archer SM, Rosenfeld RM, Schwartz SR, Barrs DM, et al. Clinical practice guideline: Sudden hearing loss. Otolaryngol Head Neck Surg 2012;146(3 Suppl): S1-35.

18) Siegel LG. The treatment of idiopathic sudden sensorineural hearing loss. Otolaryngol Clin North Am 1975;8(2):467-73.

19) Battaglia A, Lualhati A, Lin H, Burchette R, Cueva R. A prospective, multi-centered study of the treatment of idiopathic sudden sensorineural hearing loss with combination therapy versus highdose prednisone alone: A 139 patient follow-up. Otol Neurotol 2014;35(6):1091-8. 